\title{
Changes in Lipid Metabolites and Enzymes in Rat Brain Due to Ischemia and Recirculation
}

\author{
Atsufumi Moto,* Yutaka HiRAshima, Shuniro Endo, \\ AND AKIRA TAKAKU
}

Toyama Medical and Pharmaceutical University, Department of Neurosurgery, Toyama 930-01, Japan

Received June 18, 1990; Accepted November 29, 1990

\section{ABSTRACT}

Thirty and $60-\mathrm{min}$ ischemic insults resulted in an increase in free fatty acid and 1,2- diacylglycerol contents of rat forebrain. No significant changes were detected in phospholipids except phosphatidylinositol 4-monophosphate and phosphatidylinositol 4,5bisphosphate during ischemic insult. Phosphatidylinositol 4-monohosphate and phosphatidylinositol 4,5-bisphosphate contents decreased during ischemia. Although the increase in free fatty acid contents continued, 1,2-diacylglycerol did not show further increase after 30-min ischemia. These results suggest that there may be another pathway for the accumulation of free fatty acids in addition to phospholipase $C$ coupled to di- and monoacylglycerol lipase.

Free fatty acid and 1,2-diacylglycerol contents increased transiently and thereafter decreased to control levels within $90 \mathrm{~min}$ after postischemic recirculation. The decrease in arachidonic acid content preceded those of other FFA. Phosphatidylinositol 4-monophosphate and phosphatidylinositol 4,5-bisphosphate contents gradually increased after the initiation of recirculation in ischemic brains. Lysophosphatidylcholine decreased gradually after temporary increase during 15 and 5-min recirculations in 30 and 60-min ischemic groups. Phospholipase A, phospholipase $\mathrm{C}$, and di- and monoacylglycerol lipase activities did not show significant changes during

*Author to whom all correspondence and reprint requests should be addressed. 
entire course of recirculation. Total activities of lysophospholipase and acylation enzymes of lysophospholipid demonstrated 1.5-and 2.2-fold increase during 30-min recirculation.

Index Entries: Phospholipase; lysophospholipase; diacylglycerol and monoacylglycerol lipase; acylation enzymes of lysophospholipid; recirculation after ischemia.

\section{ABBREVIATIONS}

PC: phosphatidylcholine

PE: Phosphatidylethanolamine

PS: Phosphatidylserine

PI: Phosphatidylinositol

SM: Sphingomyelin

PIP: Phosphatidylinositol

4-monophosphate

$\mathrm{PIP}_{2}$ : Phosphatidylinositol 4,5-

bisphosphate

LysoPC: Lysophosphatidyl-

choline

LysoPE: Lysophosphatidylethanolamine
PLA: Phospholipase A

LPL: Lysophospholipase

PLC: Phospholipase C

DG + MG lipase: Di and Monoacylglycerol lipase

1,2-DG: 1,2-Diacylglycerol

FFA: Free fatty acid

GroPCho: sn-Glycero-3-

phosphocholine

GroPIns: sn-Glycero-3-

phosphoinositol

\section{INTRODUCTION}

Brain ischemia causes an impairment of electrical activity, depletion of energy storage (Lowry et al., 1964), and an accumulation of free fatty acids (FFA) (Bazán, 1970), lysolecithin (Sun and Foudin, 1984), and 1,2diacylglycerol (1,2-DG) (Abe et al., 1987).

Brain has a high content of lipid, mainly comprising phospholipids as the major constituents of the membranous structure. They also provide the membrane with suitable environment for the normal function of many receptors, channels, and membrane-bound enzymes. The release of FFA, lysolecithin, and 1,2-DG during ischemia is thought to be from phospholipids, and these phenomena may cause the disruption of biomembrane. Many enzymic mechanisms may be involved in the release of lipid metabolities. It has been demonstrated that the release of FFA and lysophospholipid are brought about by the increased activity of phospholipase $\mathrm{A}_{2}$ coupled to lysophospholipase (LPL) (Bazán, 1976; Edgar et al., 1982; Sun and Foudin, 1984); Abe et al. (1987) have speculated that degradation of phosphoinositides via phospholipase C (PLC) and diacylglycerol lipase enzymatic pathway may be responsible for the release of 1,2-DG and FFA during early ischemia. Phospholipase $A_{1}$ coupled with LPL, or plasmalogenase coupled with LPL, may also be involved in the liberation of FFA from phospholipids (Van den Bosch, 1982; Horrocks 
et al., 1984). Additionally, in a previous study, we have described that inactivation of reacylation enzymes of lysophospholipid contribute to the accumulation of FFA during ischemia (Hirashima et al., 1989). However, the relative contribution of these pathways during ischemia remains uncertain.

The fates of lipid metabolites during postischemic recirculation and the contributing mechanisms are also not well known. In this study, we have investigated the changes in FFA, 1,2-DG, phospholipids, including polyphosphoinositides and lysophospholipids, during postischemic recirculation using the rat 4-vessel occlusion ischemic model (Pulsinelli and Brierley, 1979). Additionally, in order to understand the mechanism of phospholipid breakdown, we have further examined the activities of related enzymes in mitochondrial, microsomal, and cytosol fractions of rat brain during recirculation. The sum of these three subcellular fractions was defined as total activities.

\section{MATERIALS AND METHODS}

\section{Animal Preparation}

Male Wistar LWH rats (Toyama Laboratory Animals Co., Toyama, Japan) weighing about $300 \mathrm{~g}$ were used in these experiments. Animals were fed ad libitum until the experiment.

Cerebral ischemia was induced by the method of Pulsinelli and Brierley (1979). Briefly, animals were anesthetized with thiopental (35 $\mathrm{mg} / \mathrm{kg}$, ip) and both vertebral arteries were occluded by cauterization. Both common carotid arteries were exposed by neck skin incision and then the wound was loosely sutured. For bipolar EEG recording, two pairs of burr holes were made on the parietal bones bilaterally (2-mm lateral from bregma) and electrodes were fixed with oxyphosphate cement. The reference electrode was inserted and sutured at the prefrontal bone. The next day, carotid arteries were exposed by gently pulling out the suture and then occluded with clips. After desired ischemia period, recirculation was started by removal of clips. EEG activities were recorded on magnetic tape (SONY NFR-3000). Analysis of the power spectrum of EEG activities was processed by BERG Fourier Analyzer (EEG TREND MONITOR OEE-7102, NIHONKODEN, Japan).

Following the ischemia or recirculation, the animals were killed by decapitation and the heads were immersed in liquid nitrogen. Then the brains were chiseled out with occasional irrigation with liquid nitrogen and stored at $-80^{\circ} \mathrm{C}$ until use.

Animals were divided into three groups as follows.

Group A; 30-min ischemia

A- -0 without recirculation

A-5 5-min recirculation

A-15 15-min recirculation 
A-30 30-min recirculation

A-90 90-min recirculation

Group B; 60-min ischemia

B-1 without recirculation

B-5 5-min recirculation

B-15 15-min recirculation

B-30 30-min recirculation

B-90 90-min recirculation

Group C; control group

C -0 decapitation without operation

C-1 decapitation after sham operation

C -2 decapitation $150 \mathrm{~min}$ after sham operation and experimental procedure.

Forty-two animals of Group A and 40 of group B that showed the following EEG changes were used for this study. The EEG of Group A was completely suppressed within $5 \mathrm{~min}$ after ischemia, and the $\theta$ wave reappeared at $30 \mathrm{~min}$ and $\alpha$ wave at $90 \mathrm{~min}$ after recirculation. Group B's EEG was completely suppressed within $5 \mathrm{~min}$ after ischemia, and only the $\theta$ wave reappeared at $90 \mathrm{~min}$ after recirculation.

\section{Preparation of Lipids from Rat Brain}

Right cerebral hemisphere of frozen brain was weighed and homogenized with $3 \mathrm{vol}$ of chilled $0.25 \mathrm{M}$ sucrose on ice. The lipid extract for assay of FFA and phospholipids was obtained from the homogenate by the method of Bligh and Dyer (1959). The lipid extracts of 1,2-DG and polyphosphoinositides was obtained by the procedures of Hauser et al. (1971) and Rehncrona et al. (1982).

\section{Analyses of Lipids}

FFA were isolated from the lipid extract by TLC using $n$-hexane/ diethyl ether/acetic acid (80/20/1, by vol) as a solvent system. Conversion into methyl esters was via diazomethane derivatization. The methylated fatty acids were analyzed by GLC on a $15 \%$ DEGS column $(0.3 \times 200 \mathrm{~cm})$ at $210^{\circ} \mathrm{C}$ with nitrogen gas as carrier gas. The amounts of the individual FFA were determined using nonadecanoic acid as an internal standard. Total FFA was defined as the sum of amounts of palmitic acid (C 16:0), stearic acid (C 18:0), oleic acid (C 18:1), arachidonic acid (C 20:4), and docosahexaenoic acid (C 22:6). Separation of phospholipids, except polyphosphoinositides, was performed according to the method of Dugan et al. (1986), using a Gilson HPLC system model with two solvent delivery pumps (Gilson Model 302). The injection port was Cotani California Rheodyne Model. The peak detection was performed at $205 \mathrm{~nm}$ with a variable wave length detector (Gilson Holochrome Model HM UV Moni- 
tor). Dupont Zorbax SIL column $(4.6 \mathrm{~mm}$ id $\times 25 \mathrm{~cm}, 5 \mathrm{~nm}$ particle) was used as the HPLC column. Each phospholipid was separated and quantified by the method of Rouser et al. (1970). 1,2-DG was separated by HPTLC with a solvent system composed of chloroform/acetone/methanol (96/4/1, by vol) (Keough et al., 1972) and the acyl groups were transmethylated with anhydrous $\mathrm{HCl} /$ methanol. Methylated FFA were analyzed by GLC. The 1,2-DG level was calculated from the expression and summary of fatty acid content divided by a factor of 2. Phosphatidylinositol 4-monophosphate (PIP) and phosphatidylinositol 4,5bisphosphate $\left(\mathrm{PIP}_{2}\right)$ were separated by TLC using silica gel plates impregnated with $1 \%$ potassium oxalate (Gonzalez-Sastre and Folch, 1968). The spots were detected by lipid scanning using TLC scanner (Shimazu CS-930), scraped and phosphorus contents determined by the method of Rouser et al. (1966).

\section{Enzyme Assays}

Left cerebral hemisphere of brain was homogenized with 9 vol of icecold $0.25 \mathrm{M}$ sucrose. Subcellular fractions were prepared by the method of Shum et al. (1979), and protein was determined by the method of Lowry et al. (1951). The procedures for enzyme assays were described in detail in our previous communication (Hirashima et al., 1989). These procedures included the following: (1) incubation of exogenous radioisotope-labeled substrate with aliquot of the subcellular fraction (2) separation of product and substrate in the reaction mixture by TLC or another method, and (3) the measurement of radioactivity of reaction product. 1-Stearoyl-2-[1- $\left.{ }^{14} \mathrm{C}\right]$ arachidonyl-GroPCho, $1-\left[1-{ }^{14} \mathrm{C}\right]$ palmitoylGroPCho, 1,2-diacyl-GroP $\left[\mathrm{U}-{ }^{14} \mathrm{C}\right]$ Ins, 1,2-di $\left[1-{ }^{14} \mathrm{C}\right]$ palmitoyl-sn-glycerol, and $\left[1-{ }^{14} \mathrm{C}\right]$ arachidonic acid were used as radioactive substrates. Individual substrates were appropriately employed for the assays of phospholipase A (PLA), LPL, phospholipase C (PLC), di and monoacylglycerol lipase (DG +MG lipase), and acylation enzymes of lysophospholipid. Separation of reaction products was carried out by TLC for the assays of PLA, LPL, DG + MG lipase, and acylation enzymes of lysophospholipid. For the assay of PLC, the product was recovered in the aqueous phase of the extraction mixture, and the radioactivity was measured after evaporation. The activities of enzymes in subcellular fractions from brain prepared after recirculation in group A were examined.

\section{Statistical Analysis}

Numerical values were statistically evaluated. We employed Dunnet's test (Dunnet, 1955) to compare the data of A-0, 5, 15, 30, 90, and B-0, 5, 15, 30, 90 vs C-1, and Wilcoxin U test (Wilcoxon, 1945) to compare the data of control groups. 


\section{Materials}

Silica gel plates were purchased from Schleicher and Schuell, Bassel, FRG. HPTLC aluminum sheet silica gel plates (Art. 5547) for the assays of polyphosphoinositides were purchased from Merck Co., FRG. 1-Stearoyl-2-arachidonyl-GroPCho, 1,2-dipalmitoyl-GroPCho, 1-palmitoyl-2lysoGroPCho, 1,2-diacyl-GroPIns, arachidonic acid, and other lipids were purchased from Funai Pharmaceutical Co., Tokyo, Japan. The radioactive reagents were products of Amersham International Ltd., Amersham, UK. Other chemicals and solvents in this study were of reagent grade.

\section{RESULTS}

\section{Changes in the Levels of FFA}

As summarized in Fig. 1, the amounts of palmitic acid (C 16:0), stearic acid (C 18:0), oleic acid (C 18:1), arachidonic acid (C 20:4), and docosahexaenoic acid (C 22:6) were $255 \pm 48,361 \pm 37,191 \pm 46,228 \pm$ 40 , and $5.2 \pm 1.7 \mathrm{nmol} / \mathrm{g}$ brain (mean $\pm \mathrm{SEM}$ ), respectively, in the C-1 brain $(n=5)$, and $226 \pm 24,381 \pm 59,227 \pm 59,293 \pm 86,6.8 \pm 2.5$ $\mathrm{nmol} / \mathrm{g}$ brain, respectively $(n=4)$, in the $\mathrm{C}-2$ brain. There were no significant differences with respect to the levels of total and individual FFA between $\mathrm{C}-1$ and $\mathrm{C}-2$ brains. In C-0 brain, however, the amounts of individual FFA were $98 \pm 13,152 \pm 14,41 \pm 13,111 \pm 13$, and $2.2 \pm 0.4$ $\mathrm{nmol} / \mathrm{g}$ brain, respectively $(n=7)$. The levels of total FFA and individual FFA, except docosahexaenoic acid and arachidonic acid, in the $\mathrm{C}-0$ brain were lower than C-1 or C-2 brain. The total FFA and almost all individual FFA significantly increased by operation alone.

During ischemia, the level of FFA further increased in the brain. The amount of FFA accumulated after 30 and 60 -min ischemia were about 1.60 and 2.14 times higher than those of $\mathrm{C}-1$ brain. The increase in individual FFA contents continued for $60 \mathrm{~min}$ after initiation of ischemia. Further, the accumulation of stearic and arachidonic acids was higher than other FFA.

After transient increase, the levels of FFA during the initial period of recirculation gradually decreased. The increment of total FFA continued within 15 and 5 min in groups A and B, respectively. Individual FFA levels, except arachidonic acid, increased within $15 \mathrm{~min}$ after recirculation in group A. The decrease of arachidonic acid preceded that of other FFA. Arachidonic acid was the only fatty acid that began to decrease within 15 min of recirculation (Fig. 1.A). Changes of FFA level of group B also showed the similar trend. The decrease of arachidonic acid initiated within 5 min after recirculation, though other FFA still increased during this period (Fig. 1.B). The total and individual FFA levels recovered control levels within 90 min of recirculation in both groups A and B. 


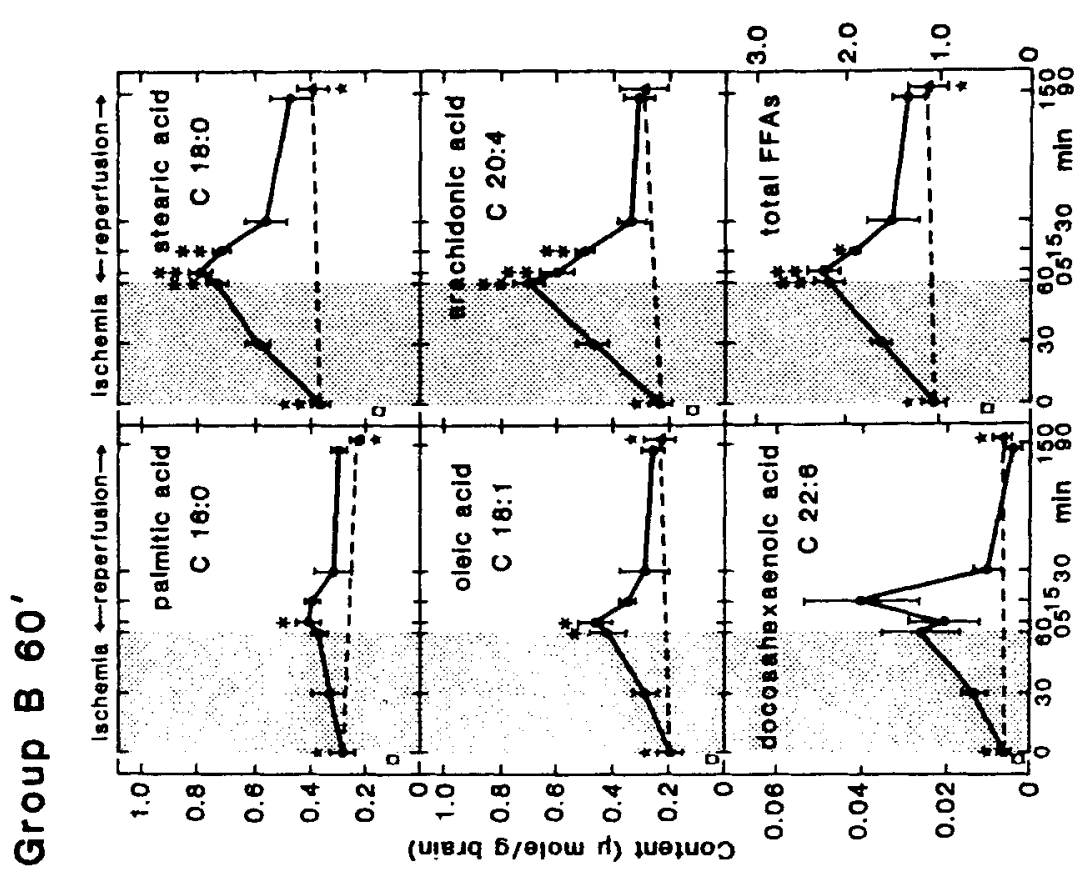

草 ठे ॥

$\ddot{\sim} \Xi$

还舅

홍

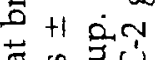
छ

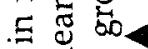

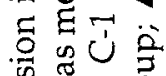
究웡용 实 월 焉 $+2$ 矛宫

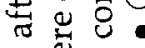
正家 西 苋䓃导总 $\dot{\oplus} \dot{0}$ 员造范 政这

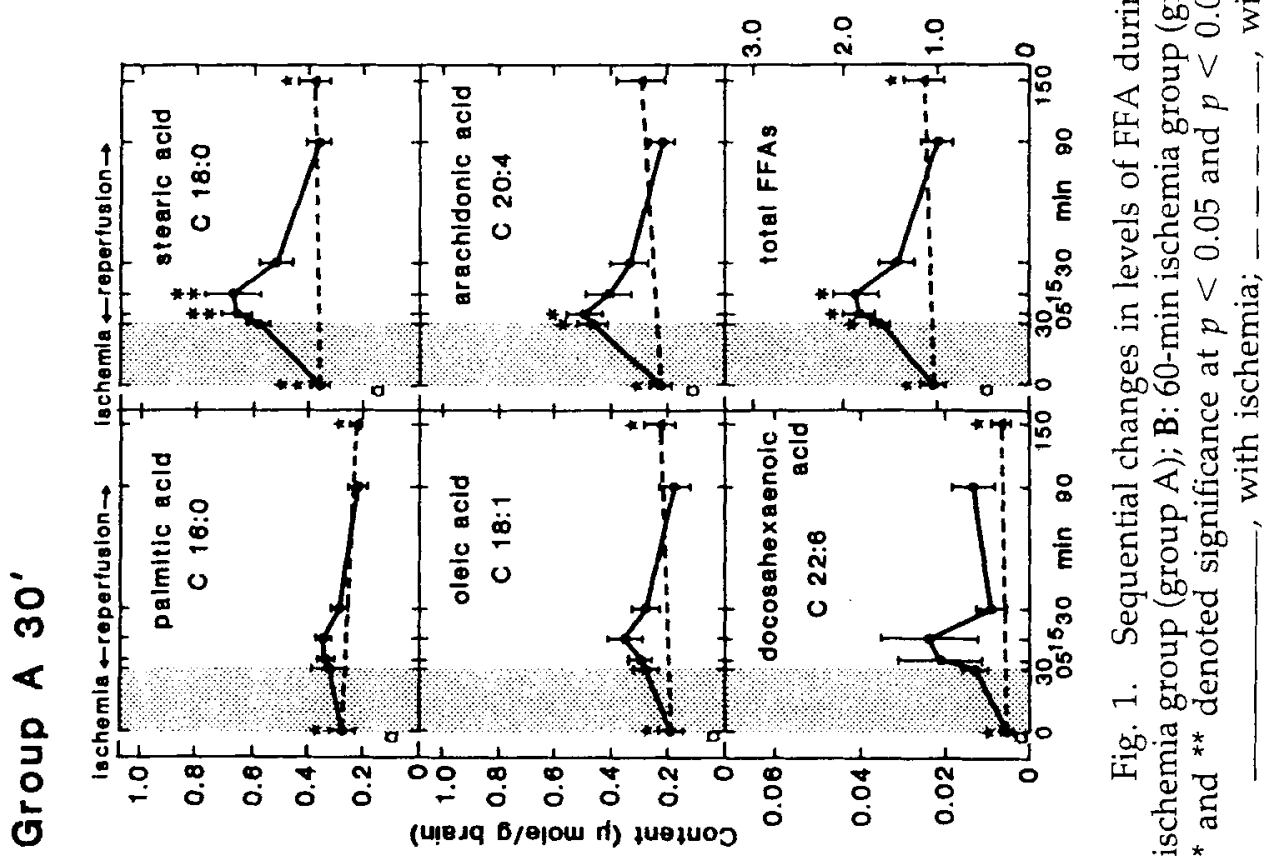




\section{Changes in the Level of 1,2-DG and Its Acyl Group Composition}

The levels of 1,2-DG in C-1 and C-2 were $69 \pm 11 \mathrm{nmol} / \mathrm{g}$ brain (mean \pm SEM, $n=6$ ) and $87 \pm 30 \mathrm{nmol} / \mathrm{g}$ brain (mean $\pm \mathrm{SEM}, n=4$ ), respectively. These values were higher than that of $C-0,56 \pm 4.3 \mathrm{nmol} / \mathrm{g}$ brain (mean \pm SEM, $n=5$ ). The level of 1,2 -DG revealed 1.81 and 1.83fold increase at 30 and $60 \mathrm{~min}$ of ischemia compared to $C-1$ value. The contents of stearic and arachidonic acids were predominant among acyl groups of 1,2-DG through ischemia (Fig. 2).

After initiation of recirculation, the content of 1,2-DG continued for 15 min followed by the decrease in both groups A and B. 1,2-DG contents were almost reversed within 90 min after recirculation. As for the acyl composition of 1,2-DG in the brain during recirculation, no changes could be detected compared to that of ischemic brain (Fig. 2).

\section{Changes in the Levels of Phospholipids and Lysophospholipids}

Regarding the level of individual phospholipids except polyphosphoinositides, statistically significant differences were not observed among three controls, C-0, C-1, and C-2. Any significant changes of phospholipids except polyphosphoinositides also could not be detected during ischemia and recirculation, though fluctuation can be observed during early period after beginning of recirculation (Table 1).

On the other hand, the levels of polyphosphoinositides were significantly different among three controls. The levels of PIP and $\mathrm{PIP}_{2}$ in C-1 and $\mathrm{C}-2$ were lower than in $\mathrm{C}-0$, suggesting that the operation caused breakdown of these phosphoinositides. The levels of PIP and $\mathrm{PIP}_{2}$ at 30 and $60 \mathrm{~min}$ after ischemia appeared to be lower than C-1, and the decrease of these polyphosphoinositides continued within 5 min after the initiation of blood supply except $\mathrm{PIP}_{2}$ level in 30-min ischemic group. Subsequently, these levels increased and normalized at $90 \mathrm{~min}$ after recirculation (Table 1 ).

There was an increasing trend in lysophospholipid levels during ischemia. After the initiation of recirculation, lysophosphatidylcholine (LysoPC) was significantly increased at $15 \mathrm{~min}$ (A) and $5 \mathrm{~min}$ (B), and decreased gradually thereafter (Fig. 3.A,B). Lysophosphatidylethanolamine (LysoPE) did not show marked changes (Fig. 3.C,D) compared to ischemic brain.

\section{Changes of Enzyme Activities}

PLA, PLC, and DG + MG lipase are $\mathrm{Ca}^{2+}$-dependent (Hirashima et al., 1989). These enzyme activities were measured at optimal $\mathrm{Ca}^{2+}$ concentration. The data were statistically evaluated by the method of Dunnet (1955). According to this evaluation, there were no significant changes during entire course of recirculation in the total activities of PLA, 


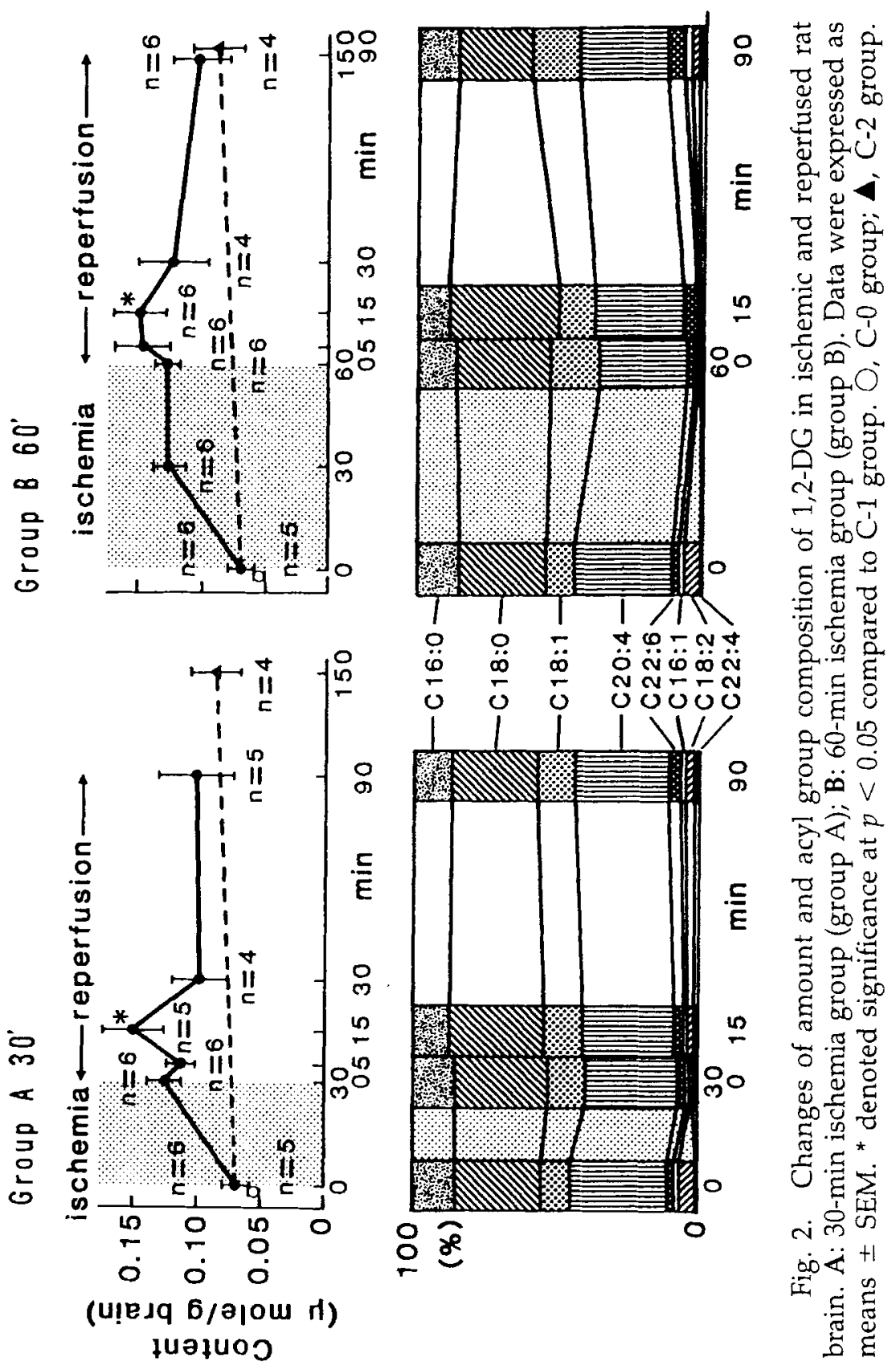




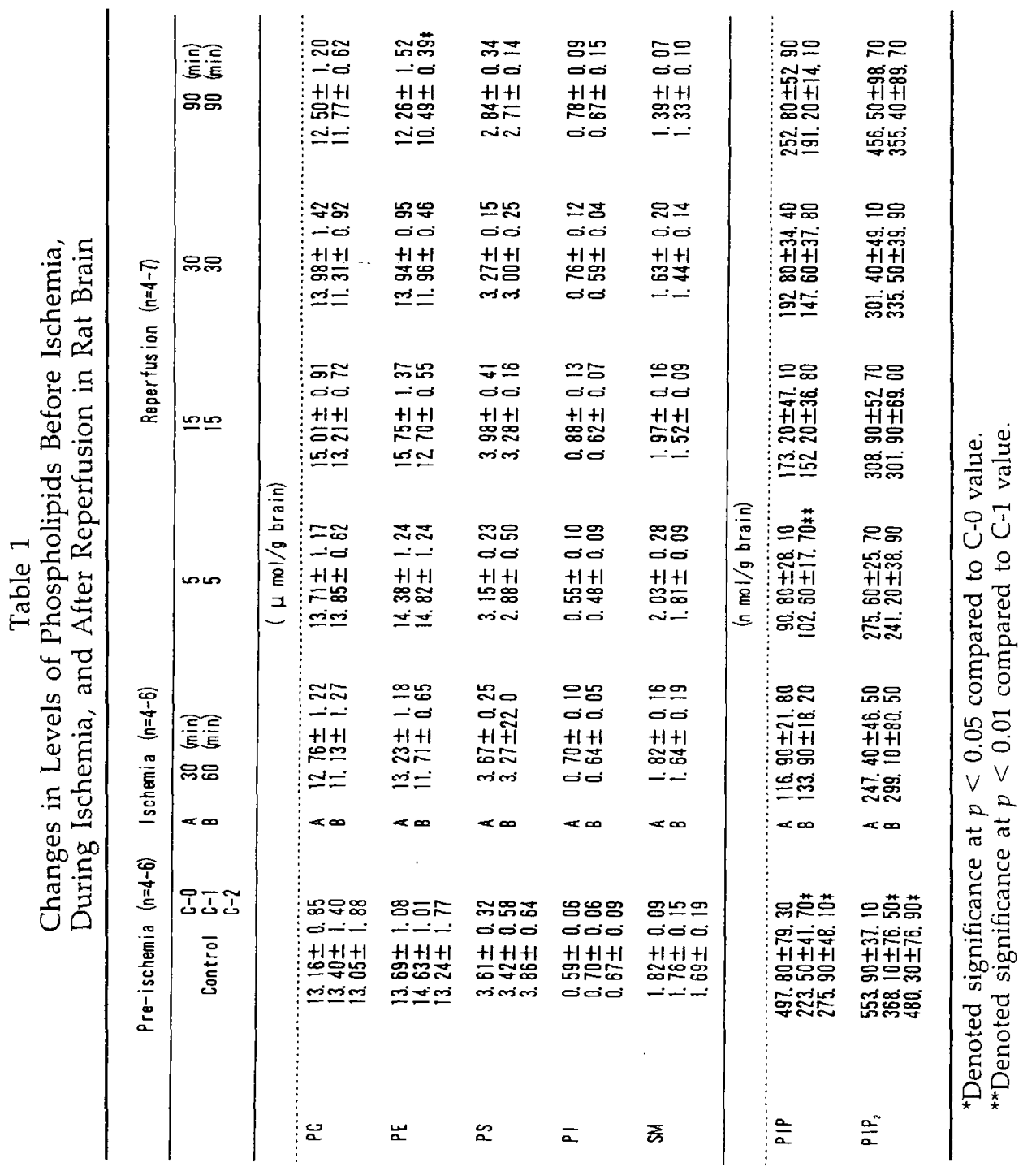




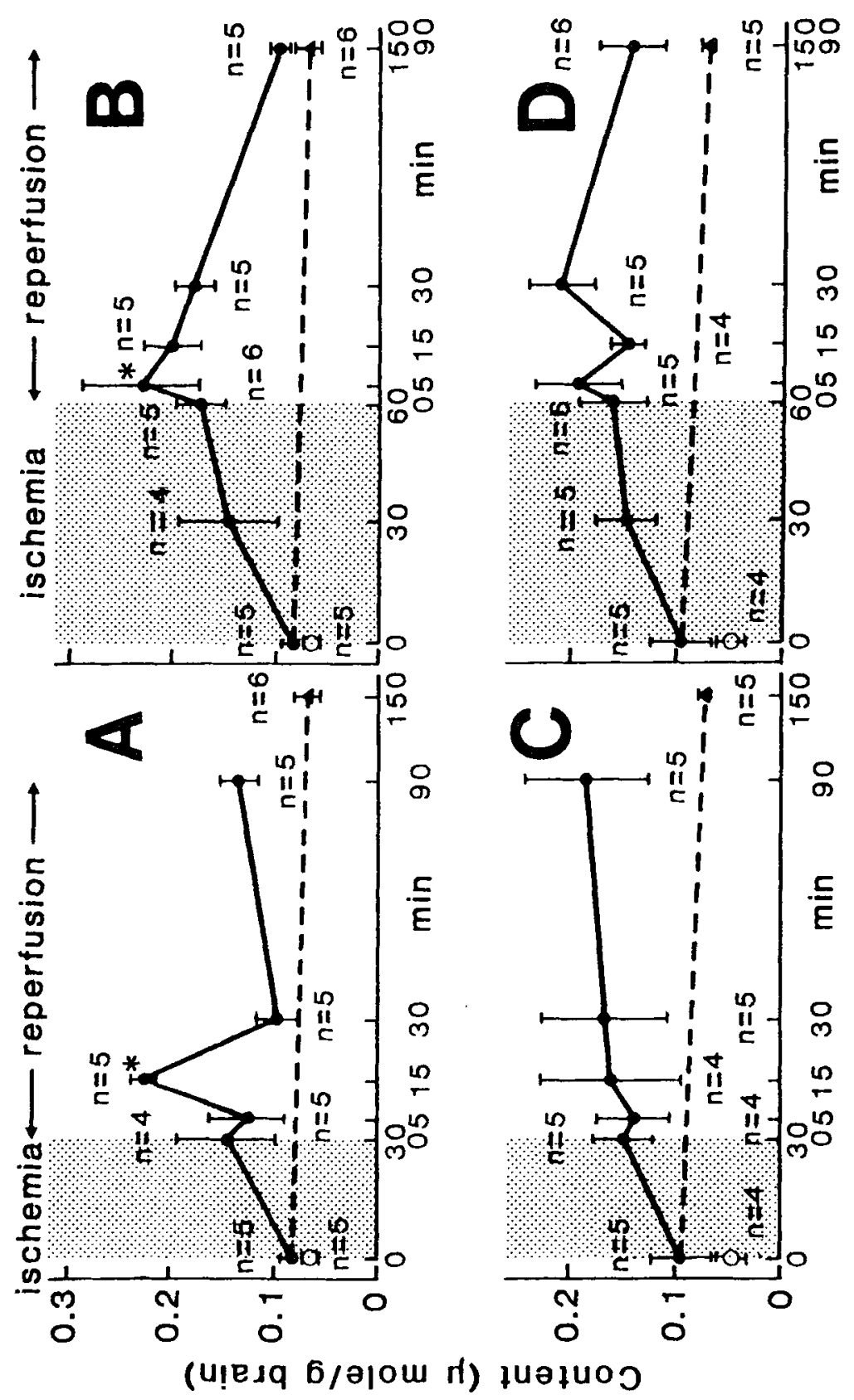
“. 元..

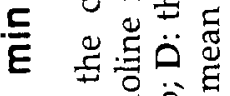

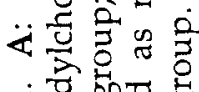

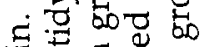
可. 苋 ○客造

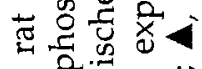

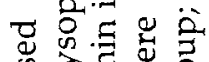
出之击芆员 㟧官 क ڤ प

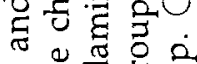

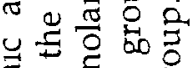
हَّ 过室宾 吕家㝴

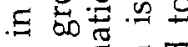
무 줄 可

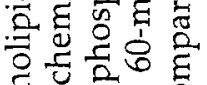
․ㅠㅇㅇㅇㅇ \% 520

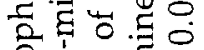
员官㟧

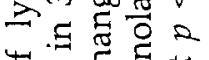
पั \&

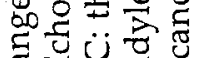

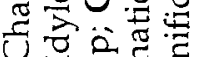

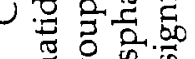
ल क की

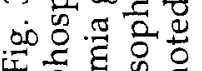

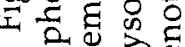
焉岕。 
LPL, PLC, and DG +MG lipase. But only acylation enzymes of lysophospholipid were activated at $30 \mathrm{~min}$ after recirculation (Fig. 4). Subcellular fraction study revealed changes in acylation enzymes of lysophospholipid and LPL during recirculation (data not shown). After the initiation of recirculation, the activities of these enzymes, except LPL of cytosolic fraction, increased gradually during $30 \mathrm{~min}$, and decreased thereafter. The acylation enzyme activities of lysophospholipid in subcellular fractions increased 1.2-2.9 times at $30 \mathrm{~min}$ after recirculation compared to the end of ischemia (data not shown). The activities of LPL at that time-point were 1.5 and 2 times higher than 30-min ischemic brain in mitochondrial and microsomal fractions, respectively. However, the cytosolic activity did not show any changes (data not shown).

\section{DISCUSSION}

\section{Lipid Metabolites in Control Brains}

To determine the alteration in the amounts of metabolites during ischemia and recirculation, we need adequate control. We have compared their levels among three controls. The data of all metabolite contents in $\mathrm{C}-1$ group agreed with $\mathrm{C}-2$ group. However, there were differences in FFA, 1,2-DG, and polyphosphoinositide contents between $\mathrm{C}-0$ and C-1 or C-2 (Figs. 1, 2, Table 1). In spinal cord injury model, the FFA levels were increased after only laminectomy (Demediuk et al., 1985). It is possible that surgical trauma and anesthesia may cause an increase of the lipid metabolites in both spinal cord and brain, probably because of changes in neurotransmitters (Knepel and Meyen, 1986; Gecse et al., 1987). In this study, group C-1 was adopted as the control group in all comparisons.

\section{Lipid Metabolites and Enzyme Activities During Ischemia}

Ischemia caused an increase in FFA and 1,2-DG levels and a decrease in polyphosphoinositides (Figs. 1, 2, Table 1). The composition of FFA and 1,2-DG liberated during ischemia were quite similar (Figs. 1, 2). The inositol-containing phospholipids has been reported to be rich in stearic and arachidonic acids (Abe et al., 1987). Our results agree with this. The action of PLC and diacylglycerol lipase on polyphosphoinositides may be important for the liberation of FFA (Abe et al., 1987). However, there were no differences in the contents of 1,2-DG and polyphosphoinositides between 30 and $60-\mathrm{min}$ in ischemic brains (Fig. 2, Table 1). This means that the degradation of polyphosphoinositides may be small at the late period of ischemia. On the other hand, the liberation of FFA increased 1.5-fold between 30 and $60 \mathrm{~min}$ of ischemia. Judging from the above results, it seems that there may be another pathway for the liberation of 


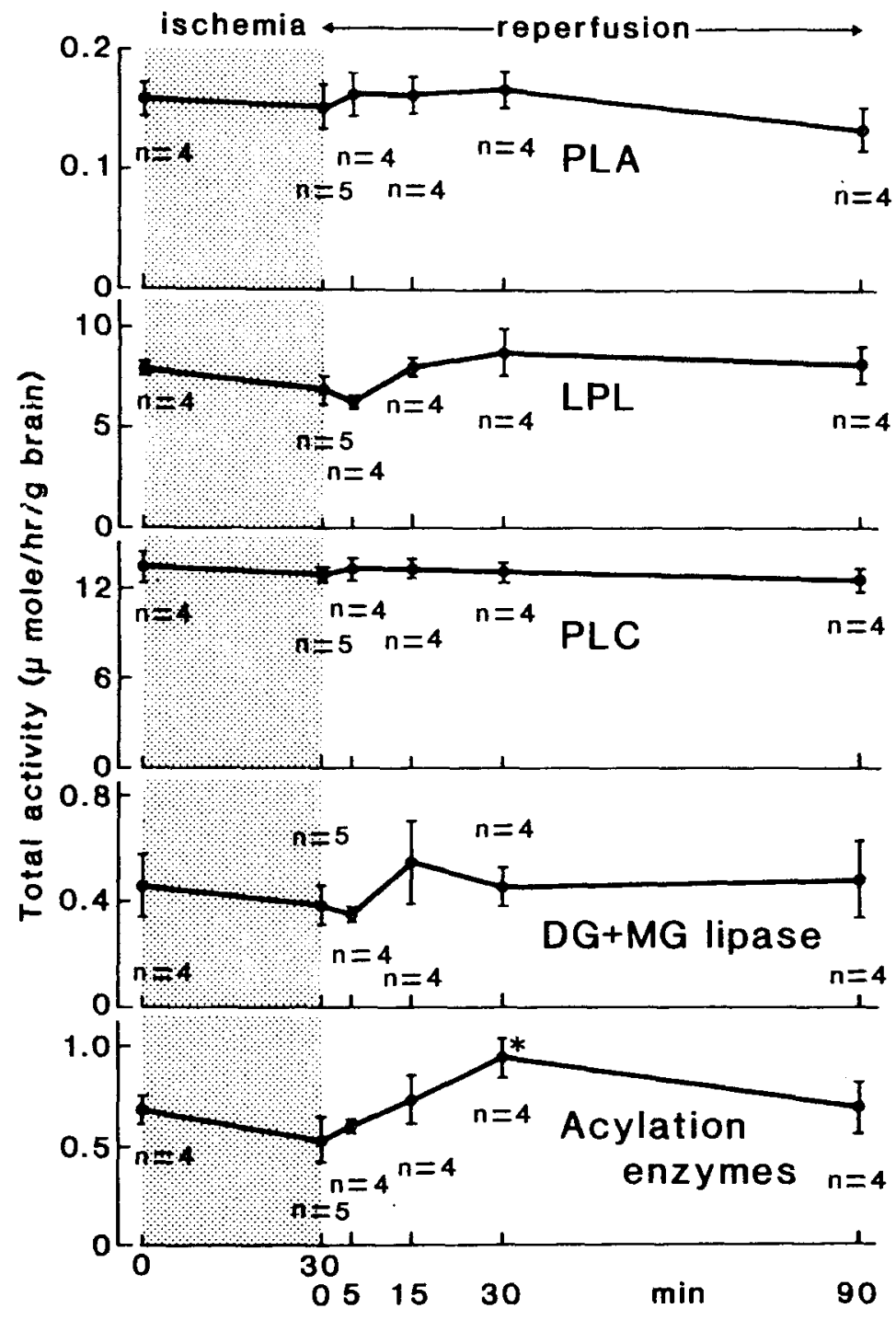

Fig. 4. Changes in total activities of individual enzymes during reperfusion in rat brain. Data were expressed as means \pm SEM. * denoted significance at $p<0.05$ compared to C-1 group.

FFA in addition to PLC coupled with DG + MG lipase, at least during late period of ischemia. No significant changes in the levels of individual phospholipids, except polyphosphoinositides, could be detected during ischemia (Table 1). In our previous report, the changes of FFA and phospholipid were measured in decapitated brain (Hirashima et al. 1989). These lipid changes agreed closely with the changes obtained from this 4-vessel occlusion model. 
For the FFA pool in brain, the alteration of acylation activity also may be important. In a previous article, we reported that inactivation of acylation enzymes of lysophospholipid during ischemia and indicated that both ATP exhaustion and inactivation of these enzymes may be involved in the accumulation of FFA and lysophospholipids during ischemia (Hirashima et al., 1989). In the present study, we could not find a statistically significant increase in lysophospholipids during ischemia. However, there was a trend toward increased lysophospholipid content.

\section{Lipid Metabolites and Enzyme Activities During Recirculation}

Total FFA levels increased transiently during early period of recirculation, and thereafter decreased toward control values within $90 \mathrm{~min}$. Interestingly, the decrease of arachidonic acid preceded those of other FFA (Fig. 1). Arachidonic acid has been known to be peroxidized enzymically during postischemic recirculation to produce prostaglandins and leukotrienes (Gaudet and Levine, 1979; Morskowitz et al., 1984). Polyunsaturated FFA, such as arachidonic acid, may also be peroxidized nonenzymically (Mead, 1976). It is possible that these pathways may be responsible for the decrease of arachidonic acid during recirculation. Recently, Yoshida et al. (1986) proposed the role of triacylglycerol, which can trap the excess of free arachidonic acid by acyl-exchange reaction. Rehncrona et al. (1982) also measured FFA and phospholipids during postischemic recirculation. However, they did not detect the increase of FFA during initial recirculation period, but demonstrated the same tendency in arachidonic acid during recirculation.

In our earlier study, the activity of acylation enzymes of lysophospholipid decreased during ischemia (Hirashima et al. 1989). This activity comprises the reactions catalyzed by two different enzymes, acylCoA synthetase, which is ATP-dependent, and AcylCoA:lysophospholipid acyltransferase. These enzymes may also play an important role in the decrease of FFA during postischemic recirculation. After the recirculation, the total activity of acylation enzymes of lysophospholipid gradually increase within $30 \mathrm{~min}$. From the above result, it is possible that recovery of acylation enzymes themselves, as well as that of ATP, may contribute to the elimination of FFA during recirculation. LysoPC has been shown to inhibit the action of acylCoA:lysophospholipid acyltransferase by direct interaction (Wittels and Hurlbert, 1977; Sun et al., 1978; Weltzien, 1979). In the previous communication, we have speculated that the increase of lysocompounds may inhibit acylation enzymes during ischemia (Hirashima et al. 1989). In this study, total and some subcelullar lysophospholipase activities have been shown to increase during recirculation compared to the activity at the end of ischemia (data not shown). Although LysoPC level increased temporarily at initial recirculation period, thereafter, it decreased gradually. These 
results suggest a possible mechanism recovery of acylation enzymes during recirculation, namely, the decrease of LysoPC probably as a result of activation of LPL during recirculation may release suppressed activity of acylation enzyme.

Recirculation after both 30 and 60 min of ischemia reversed the levels of 1,2-DG and polyphosphoinositides toward control levels within 90 min (Fig. 2, Table 1). 1,2-DG level in the brain declined rapidly after 15min recirculation in both ischemic groups, whereas the polyphosphoinositide levels increased gradually during the entire course of recirculation (Fig. 2, Table 1). Yoshida et al. (1986) have demonstrated the trend toward increased phosphatidic acid during initial recirculation after prolonged ischemia. Therefore, it is possible that the decrease of 1,2-DG may be related to the activation of DG kinase accompanied by the restoration of ATP. They have also indicated that not only kinases toward inositolcontaining phospholipids, but also de novo synthesis may contribute to syntheses of polyphosphoinositides during postischemic recirculation (Yoshida et al., 1986). In this study, however, we could not obtain evidence that the de novo synthesis was via phosphatidic acid and CDPdiacylglycerol. The pathway catalyzed by choline or ethanolamine phosphotransferase should also be considered for the elimination of 1,2DG during recirculation. Therefore, these enzymes may catalyze the reactions between CDP-amines and 1,2-DG (DeMedio et al., 1980) and decrease the contents of 1,2-DG that were accumulated during ischemia.

\section{ACKNOWLEDGMENTS}

The authors wish to thank K. Hiraga for helpful advices and comments. The authors also wish to thank R. Kato for technical assistance and $\mathrm{Y}$. Nakayama and M. Kanayama for preparing the manuscript for publication. This work was supported, in part, by a scientific grant (No. 59570610) from the Ministry of Education, Science and Culture, Japan.

\section{REFERENCES}

Abe K., Kogure K., Yamamoto H., Imazawa, M., and Miyamoto, K. (1987) Mechanism of arachidonic acid liberation during ischemia in gerbil cerebral cortex. J. Neurochem. 48, 503-509.

Bazán N. G. (1970) Effect of ischemia and electroconvulsive shock on free fatty acid pool in the brain. Biochim. Biophys. Acta 218, 1-10.

Bazán N. G. (1976) Free arachidonic acid and other lipids in the nervous system during early ischemia and after electroshock. Adv. Exp. Med. Biol. 72, 317335.

Billah M. M., Lapetina E. G., and Cuatrecasas P. (1981) Phospholipase activity specific phosphatidic acid. A possible mechanism for the production of arachidonic acid in platelets. J. Biol. Chem. 256, 5388-5403. 
Bligh E. G. and Dyer W. J. (1959) A rapid method of total lipid extraction and purification. Can. J. Biochem. Physiol. 37, 911-917.

DeMedio G. E., Goracci G., Horrocks L. A., Lazarewicz J. W., Mazzari S., Porcellati G., Strosznajder J., and Trovarelli G. (1980) The effect of transient ischemia on fatty acid and lipid metabolism in the gerbil brain. Ital. J. Biochem. 29, 412-432.

Demediuk P., Saunders R. A., Clendenon N. R., Means E. D., Anderson D. K., and Horrocks L. A. (1985) Changes in lipid metabolism in traumatized spinal cord. Prog. Brain Res. 63, 211-226.

Dugan L. L., Demediuk P., Pendley II C. E., and Horrocks L. A. (1986) Separation of phospholipids by high-performance liquid chromatography: All major classes, including ethanolamine and choline plasmalogens, and most minor classes, including lysophosphatidylethanolamine. J. Chromatogr. 378, 317-327.

Dunnett C. W. (1955) A multiple comparison procedure for comparing several treatments with a control. J. Amer. Statist. Ass. 50, 1096-1121.

Edgar A. D., Strosznajder J., and Horrocks L. A. (1982) Activation of ethanolamine phospholipase $\mathrm{A}_{2}$ in brain during ischemia. J. Neurochem. 39, 1111-1116.

Gaudet R. J. and Levine L. (1979) Transient cerebral ischemia and brain prostaglandins. Biochem. Biophys. Res. Commun. 86, 893-901.

Gecse A., Mezei A., and Telegdy G. (1987) Neuropeptides and arachidonate cascade in the central nervous system. Front. Horm. Res. 15, 299--323.

Gonzalez-Sastre F. and Folch J. (1968) Thin-Layer chromatography of the phosphoinositides. J. Lipid Res. 9, 532, 533.

Hauser G., Eichberg J., and Gonzales-Sastre F. (1971) Regional distribution of polyphosphoinositides in rat brain. Biochem. Biophys. Acta 248, 87-95.

Hirashima Y., Moto A., Endo S., and Takaku A. (1989) Activities of enzymes metabolizing phospholipids in rat cerebral ischemia. Mol. Chem. Neuropathol. 10, 87-100.

Horrocks L. A., Dorman R. V., and Porcellati G. (1984) Fatty acid and phospholipids in brain during ischemia, Cerebral Ischemia (Bes A., Braquet P., Paoletti R., and Siesjö B. K., eds.) pp. 212-222, Excerpta Medica, Congress Series 654, Elsevier, Amsterdam.

Keough K. M. W., Macdonald G., and Thompson W. (1972) A possible relation between phosphoinsitides and the diglyceride pool in rat brain. Biochem. Biophys. Acta 270, 337-347.

Knepel W. and Meyen G. (1986) Effect of various blockers of arachidonic acid metabolism on release of beta-endorphin and adrenocorticotropin-like immunoreactivity induced by phospholipase $\mathrm{A}_{2}$ from rat adenohypophysis in vitro. Neuroendocrinology 43, $44-48$.

Lowry O. H., Rosebrough N. J., Farr A. L., and Randall R. J. (1951) Protein measurement with Folin phenol reagents. J. Biol. Chem. 193, 265-275.

Lowry O. H., Passonneau J. V., Hasselberger F. X., and Schulz D. W. (1964) Effect of ischemia on known substrates and cofactors of the glycolytic pathway in brain. J. Biol. Chem. 239, 18-30.

Mead J. F. (1976) Free radical mechanisms of lipid damage and consequences for cellular membranes, in Free Radicals in Biology (Pryor W. A., ed.), vol. 1, pp. 51-68, Academic, New York. 
Moskowitz M. A., Kiwak K. J., Hekimian K., and Levine L. (1984) Synthesis of compounds with properties of leukotriens $\mathrm{C}_{4}$ and $\mathrm{D}_{4}$ in gerbil brains after ischemia and reperfusion. Science 224, 886-889.

Pulsinelli W. A., and Brierley J. B. (1979) A new model of bilateral hemispheric ischemia in the unanesthetized rat. Stroke 10, 267-272.

Rehncrona S., Westerberg E., Akesson B., and Siesjö B. K. (1982) Brain cortical fatty acids and phospholipids during and following complete and severe incomplete ischemia. J. Neurochem. 38, 84-93.

Rouser G., Siakotos A. N., and Fleischer S. (1966) Quantitative analysis of phospholipids by thin layer chromatography and phosphorus analysis of spots. Lipids 1, 85-86.

Shum T. Y. P., Gray N. C. C., and Strickland K. P. (1979) The deacylation of phosphatidylinositol by rat brain preparations. Can J. Biochem. 57, 13591367.

Sun G. Y., Su K. L., Der O. M., and Tang W. (1978) Enzymic regulation of arachidonate metabolism in brain membrane phosphoglycerides. Lipids 14, 229-235.

Sun G. Y. and Foudin L. L. (1984) On the status of lysolecithin in rat cerebral cortex during ischemia. J. Neurochem. 43, 1081-1086.

van den Bosch H. (1982) Phospholipases, in Phospholipids (Hawthorne J. N. and Ansell G. B., eds.), pp. 313-357, Elsevier Biomedical, Amsterdam.

Weltzien H. U. (1979) Cytolytic and membrane perturbing properties of lysophosphatidylcholine. Biochim. Biophys. Acta 559, 259-287.

Wilcoxon F. (1945) Individual comparisons by ranking methods. Biometrics 1, 8083.

Wittels B. and Hurlbert S. (1977) Enzyme affinity in the acylation of lysophosphatidylcholine. Biochim. Biophys. Acta 489, 72-78.

Yoshida S., Ikeda M., Busto R., Santiso M., Martinez E., and Ginsberg M. D. (1986) Cerebral phosphoinositide, triacylglycerol, and energy metabolism in reversible ischemia: Origin and fate of free fatty acids. J. Neurochem. 47, 744757. 